\title{
Editorial
}

\section{MI ÚLTIMA EDITORIAL}

Esta es mi última editorial para la Revista Chilena de Radiología, luego de haber participado en el comité editorial por muchos años y dirigido nuestra revista durante 3 años, con un total de 12 números, en los que el foco ha estado en los radiólogos generales de habla hispana. Siempre es bueno reconocer los pasos dados, y este ha sido un gran paso para mi desde el punto de vista profesional. Mi agradecimiento sincero para el comité editorial y especial agradecimiento a Sonia Rivas por su abnegada labor. Durante estos años y luego de un proceso difícil con una casa editorial de marca mundial, estamos volviendo a una alternativa regional dada por Scielo Brasil junto con al trabajo de Paulina y Patricio Gana para tener hoy una revista que recibe artículos de toda Latinoamérica y de la que nos sentirnos orgullosos.

Dedico esta esta última editorial a los autores y revisores, especialmente a aquellos que no lo son aún.

Sobre nuestros futuros autores, están aquellos que no publican porque se desempeñan en un entorno donde los casos interesantes parecen ser menos interesantes o insuficientes para fundamentar una publicación científica. Para ellos, buenas noticias: los casos extraordinarios se dan de norte a sur y nuestros derivadores, aunque son pocos por especialidad y subespecialidad si comparamos con otros países de la región, están cada día mejor conectados, facilitando el seguimiento de nuestros hallazgos. En la vereda opuesta, están los colegas que forman parte de centros de gran tamaño, universitarios, públicos o privados, y que, con mayores oportunidades para la recolección y redacción, destinan su esfuerzo a revistas internacionales. Para ellos, un llamado: "jayúdennos!". Nuestra revista está preparada para las "ligas mayores”, pero esta meta seguirá aplazándose mientras no aumentemos el nivel intelectual de nuestras comunicaciones. Es posible que el factor de impacto sea menor que el obtenido en una revista extranjera, pero mientras elevamos nuestros indicadores bibliomédicos, los pacientes y médicos que hayan leído sus publicaciones en nuestra lengua nativa no tendrán problema en acompañarlos en la espera, después de haberlos elegido porque conocen las enfermedades que los aquejan y preocupan.

Sobre los revisores, mi mayor agradecimiento por la labor silenciosa y dedicada. No es fácil ver pasar por nuestras manos la publicación sobre el tema en el que justo estábamos trabajando. "Sin revisores no hay ciencia”, dijo el profesor Richard Catflow en la editorial de diciembre de la Revista Nature1. Los revisores tienen la tremenda responsabilidad de elevar el nivel de las publicaciones, con comentarios nutritivos y contribuciones generosas y desinteresadas.

Ser parte del desarrollo científico de una comunidad, requiere gusto, trabajo y compromiso, sin duda, pero el avance debe ser protocolar, guiado por una estructura que permita a nuestros equipos de trabajo un actuar coordinado, facilitando la transmisión de información. Lo que nos separa intelectualmente de los países desarrollados puede resumirse en tres frases sencillas, pero que cambiarían nuestro andar colectivo por la ciencia: "seguir instrucciones simples", "hacer lo que dijimos que íbamos a hacer" y "controlar que las tareas comprometidas efectivamente están hechas". Aplicadas al trabajo editorial del día a día implicarían rigurosidad y respeto por los procesos y sus plazos.

Tenemos en nuestro país un enorme capital intelectual que requiere ser invertido y compartido. Nuestra patología es en muchas áreas similar a las del primer mundo y en varias otras muy especial, debido a nuestras particularidades geográficas, genéticas y culturales. El futuro se presenta motivante y con espacio para todos, con publicaciones académicas cuyo nivel debiera seguir creciendo con la evolución de la tecnología y su progresivo mayor acceso, atrayendo cada vez a más autores y lectores. Le deseo mucha suerte al Dr. Juan Pablo Cruz, quien, durante los próximos 4 años, liderará un equipo editorial con un potencial extraordinario.

Marcelo Gálvez Moya

Editor científico

Clínica Las Condes. Santiago - Chile.

${ }^{\star}$ Correspondencia: mgalvez@ clc.cl

\section{Referencias}

1. R. Catlow. Peer reviewers need more nurturing. Nature,2017:552; 293. https://www.nature.com/articles/d41586-01708289-z 